\title{
Effects on Compressive and Tensile Strength of Concrete by Replacement of Natural Aggregates with various Percentages of Recycled Aggregates
}

\author{
Sadaf Noshin $^{1 \mathrm{a}}$, Muhammad Shahzad Aslam ${ }^{\text {1b }}$, Humaira Kanwal ${ }^{1 \mathrm{c}}$, \\ Muhammad Adil Khan' ${ }^{1 d}$, Abrar Ahmad ${ }^{2}$
}

RECEIVED ON 07.01.2020, ACCEPTED ON 05.05.2021

\begin{abstract}
Recycled aggregate concrete is required owing to environmental conservation and actual consumption of resources. In the construction industry, for the manufacturing of concrete the demand for replacement of ordinary aggregates by recycled aggregates has increased worldwide due to the large quantity of structure and destruction waste. The objectives of this research is to evaluate the effects of strength of concrete by replacing the normal crush with different percentages such as $25 \%, 50 \%, 75 \%$ and $100 \%$ of recycled aggregates. To conduct this study, a total of 120 cylinders (60 for compression and 60 for splitting cylinder test) are casted with mixing ratio of 1:1.9:3.8 and water to cement ratio of 0.59 while curing is carried out for 7, 14, 21 and 28 days. Numerous laboratory tests are performed like workability test, compression tests and splitting tensile strength tests, to check and compare effects of the recycled aggregate concrete with reference mix M1 (0\% RA). The results illustrate that the workability of concrete decreases when the quantity of recycled aggregates are increased due to more water absorbing capacity. Further, it is also perceived that the compressive strength of concrete is decreased by $3.8 \%, 5.7 \%, 12.9 \%$, and $15.8 \%$ respectively at 28 days of curing by substituting coarse aggregates with various percentages such as $25 \%, 50 \%, 75 \%$ and $100 \%$ of recycled aggregates as compared to reference concrete mix M1 $(0 \% \mathrm{RA})$. Similarly, splitting tensile strength is also decreased when the quantity of recycled aggregates in ordinary concrete is increased. Moreover, this reduction in workability and strength of concrete is due to more water absorbing capacity of recycled aggregates. Hence it is concluded from the research that up to $25 \%$ replacement of natural aggregate with recycled aggregates, the recycled aggregate concrete is usually preferable to reduce the cost of construction as well as improve the environmental pollution issues. It is also observed that the splitting tensile strength of a concrete batch should vary between $9-11 \%$ of its respective compressive strength test results.
\end{abstract}

Keywords: Ordinary Concrete, Recycled Aggregate Concrete, Recycled Aggregates, Workability Test, Compression Test, Splitting Tensile Strength Test

\section{INTRODUCTION}

onstruction industry and other constituencies are responsible for maintaining the sustainability within the environment, owing to a strong social request [1]. The biggest left over in the world is the building and destruction waste. It is very difficult to dispose off such huge quantities of construction and demolition waste because it disturbs the environmental sustainability and its disposal affects the preservation of natural assets through avoiding diggings of raw material Landfilling is the

${ }^{1}$ Department of Civil Technology, The University of Lahore, Lahore, Pakistan.

Email: ${ }^{a}$ sadaf.noshin@ tech.uol.edu.pk (Corresponding Author), ${ }^{\mathrm{b}}$ muhammad.aslam5 @ tech.uol.edu.pk,

chmughal84@gmail.com, dadee.uol@gmail.com

${ }^{2}$ National Transmission and Dispatch Company (NTDC), Lahore, Pakistan. Email: abrar.engr@ ntdc.com.pk

This is an open access article published by Mehran University of Engineering and Technology, Jamshoro under CC BY 4.0 International License. 
best solution for the disposal of such waste but due to huge volume, it increases the burden on stacking and process of landfills. Sometimes environmental pollution is produced over time due to the presence of hazardous left over in construction and demolition waste. As a substitute, reprocessing or recycling offerings a chance to organize construction and harmless residue. Recycling is considered as the best process as it not only reduces waste but also has many benefits such as reduction in the requirement for natural materials, decrease in transport and disposal cost, conservation of property for upcoming metropolitan expansion, improvement of ecological sustainability, and increase in job rate that should be available for handling the construction and demolition waste on traditional landfilling sites [2-5].

It is notably observed that as the construction and progress of frugality is enhanced every year, the measure of manufacture and devastation waste has also increased. All the construction waste was discarded in landfills due to their non-recyclable characteristics except the recyclable materials such as plastic, glass, and scrap metal, thus it leads to several landfill difficulties for example unavailability of land and surplus excess [6]. As the demand for coarse aggregate has increased gradually due to requirement for economies expansion as it is the most commonly used construction material that constitute about the 3/4th of the concrete. [7, 8] .The usage of natural materials and the burden on landfills due to excessive construction waste has reduced. Due to ecological benefits and cost effectiveness, the consumption of recycled coarse aggregates in the manufacturing of concrete has increased. This type of aggregates contribute to reduce land- fill capacity and maintain the sustainability as well as preserve the natural construction materials [7]. But due to their elongated and angular shape and enhanced water absorption capacity, they are rarely used in construction industry; as a substitute, they are required as filler material in highway construction and in those construction where high strength is not mandatory [9].

Recycled Aggregates are used as partially or fully as substitution of coarse and fine aggregates in recycled aggregate concrete. Though, recycled aggregate concrete is used for low level construction applications but it is cost effective, maintains the environmental sustainability and reduces the landfill management issues [10-13]. It is assumed that utilization of recycled aggregates in concrete manufacturing has been started since 1945.The reason being that during World War II a huge amount of infrastructures were damaged and the requirement for coarse and fine aggregates to reconstruct the structures were increased. They suffered problems such as reduction of natural resources, shortage of mechanical technologies for cutting of rocks, strong conservational rules and landfill management issues which stimulate the utilization of recycled aggregates. Adnan and Fawzy examined the effects of recycled aggregate concrete on workability and strength of concrete. However, the results showed that workability of concrete was reduced when the percentage replacement of recycled aggregates increased and similarly compressive strength of recycled aggregate concrete was also reduced. It was also observed that there is no significant variation in compressive strength of recycled aggregate concrete as the percentage of recycled aggregate is increased. Further investigation revealed that recycled coarse aggregates did not give better strength when they are used up to $25 \%$ of natural coarse aggregates $[12,14]$. This recycling approach of construction waste will not only reduce the overall cost of structure but also control environmental pollution, maintain sustainability and preserve natural assets [15]. Consequently, it is considerably very important to suggest the appropriate construction approaches for the utilization of waste building materials in concrete production industry [16].

The key objectives of this work are to check the workability and strength (compressive \&splitting tensile) of concrete by the replacement of natural coarse aggregates with various percentages $0 \% 25 \%$, $50 \%, 75 \%$ and $100 \%$ of recycled coarse aggregates separately at 7, 14, 21 and 28 days of curing.

\section{MATERIALS}

- Maple leaf is the easily available OPC brand which is used for the production of concrete. To maintain the quality and achieve the required strength. It is essential to acquire the cement from 
a single retailer for the complete research.

- Chenab sand is the locally available fine aggregate which is used in concrete making and its calculated fineness modulus is 2.55 .

- In this research, Margalla crush is used as coarse aggregate. Sieve analysis is an experiment that is performed to achieve the required dimension of coarse aggregates (20mm down). In this research, demolished construction material such as R.C.C slab, beam and column is used as recycled coarse aggregate. The calculated size of recycled and normal coarse aggregates which is obtained from sieve analysis having standard ASTM C136 is 20 and $11 \mathrm{~mm}$ down.

- The normal tap water that is suitable for drinking having $\mathrm{PH}$ ranges 6-8 is used.

\section{METHODOLOGY}

Concrete mix design (ACI Code 211.91-09) is carried out after material testing using prescribed ASTM Standards (ASTM C191 - 04 for Initial and final setting time of cement, ASTM C136 for Sieve analysis, ASTM C127-14 for Specific Gravity of aggregates, ASTM C29 for Bulk Density of aggregates, ASTM C33 for aggregates selection, and ASTM C192 for Specimen preparation of Concrete) and manufacturing of concrete is carried out for nominal design strength of $21 \mathrm{MPa}$ (3000Psi) with mixing ratio of $1: 1.8: 3.9$ and $\mathrm{W} / \mathrm{C}$ of 0.59 .Five mixes were prepared by the replacement of normal coarse aggregates with five percentages of recycled aggregates including $0,25,50,75$ and $100 \%$ respectively and tested at the ages of 7, 14, 21 and 28 days of curing. Hence, 120 cylinders (60 for compression test (ASTM C39) and 60 for splitting tensile strength test (ASTM C496 and BS 1881 117-
83) were casted and tested in this phase. The mixing detail and cylinder casting schedule is shown in Table 1 and Table 2.

\begin{tabular}{|c|c|l|}
\hline \multicolumn{3}{|c|}{ Table 1: Replacement Detail of Coarse Aggregate } \\
with R.A.
\end{tabular}

\section{RESULTS AND DISCUSSION}

All the experiments are executed to examine the influence of various recycled coarse aggregate replacement ratios on the workability and compressive and splitting tensile strength of concrete.

\subsection{Workability Test}

Workability in concrete structure can be defined as the ease through which concrete pours. The slump cone test and compaction factor test are commonly used experiments which are used to check the workability of concrete. The normal value of slump for foundations, slab, beam and column ranges from $50 \mathrm{~mm}$ to $75 \mathrm{~mm}$ and ASTM C 143 standard is used for its measurement. The normal values of compaction factor usually range from 0.7 to 0.95 . This test is performed as per specification standard of IS1199:1999. The measuring process of slump cone

\begin{tabular}{|c|c|c|c|c|c|c|c|c|c|}
\hline \multicolumn{10}{|c|}{ Table 2: Casting Detail } \\
\hline \multirow[t]{3}{*}{ S.No. } & \multirow{3}{*}{$\begin{array}{l}\text { Type of } \\
\text { Mixes }\end{array}$} & \multicolumn{8}{|c|}{ Age of Concrete } \\
\hline & & \multicolumn{4}{|c|}{ Compression Test } & \multicolumn{4}{|c|}{ Splitting Tensile Strength Test } \\
\hline & & 7 days & 14 days & 21 days & 28 dats & 7 days & 14 days & 21 days & 28 days \\
\hline P cone1 & M1 & 3 & 3 & 3 & 3 & 3 & 3 & 3 & 3 \\
\hline 2 & M2 & 3 & 3 & 3 & 3 & 3 & 3 & 3 & 3 \\
\hline 3 & M3 & 3 & 3 & 3 & 3 & 3 & 3 & 3 & 3 \\
\hline 4 & M4 & 3 & 3 & 3 & 3 & 3 & 3 & 3 & 3 \\
\hline 5 & M5 & 3 & 3 & 3 & 3 & 3 & 3 & 3 & 3 \\
\hline
\end{tabular}


test and compaction factor test is shown in Fig. 1(a) and Fig.1 (b).

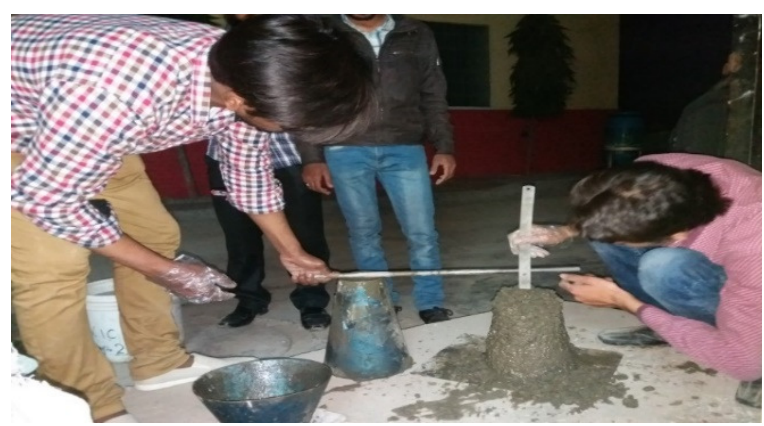

Fig.1 (a): Measuring Slump of Concrete

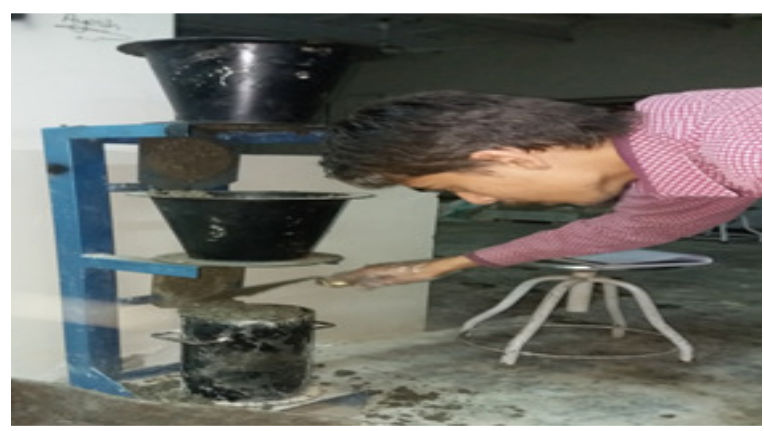

Fig. 1(b): Compaction Factor Test

The test results show that the workability of specimen is decreased via increasing the percentage of recycled aggregates in concrete. It is clear from the results shown in Figs.2-3, the values of workability test of mix M1 (0\% of recycled aggregate) is maximum as compared to mix M5 (100\% of recycled aggregate). The slump values for mix M5 (100\% of recycled aggregate) shows a reduction of $18.18 \%$ as compared to mix M1 ( $0 \%$ of recycled aggregate) and similarly for compaction factor values shows a reduction of $10.54 \%$. The reason of reduction in workability is due to the more water absorbing capacity of recycled aggregates. To overcome this problem, the recycled coarse aggregates should be soaked in water approximately for twenty to thirty minutes before mixing of concrete [17].

\subsection{Compressive Strength}

The maximum resistance produced in concrete cylinders by applying the uniform axial load is called the compressive strength of concrete. Five concrete

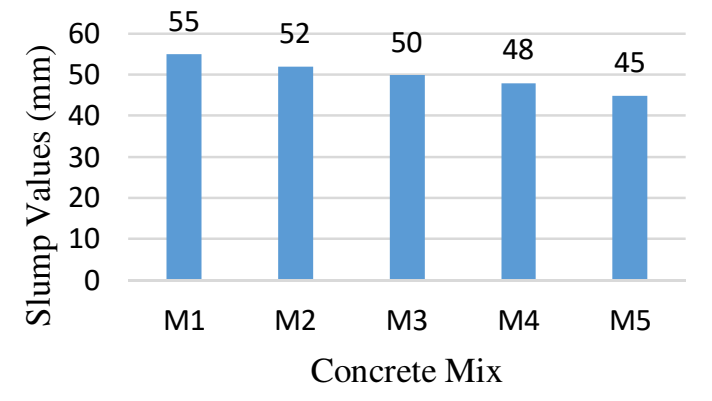

Fig. 2: Slump values for different concrete mix

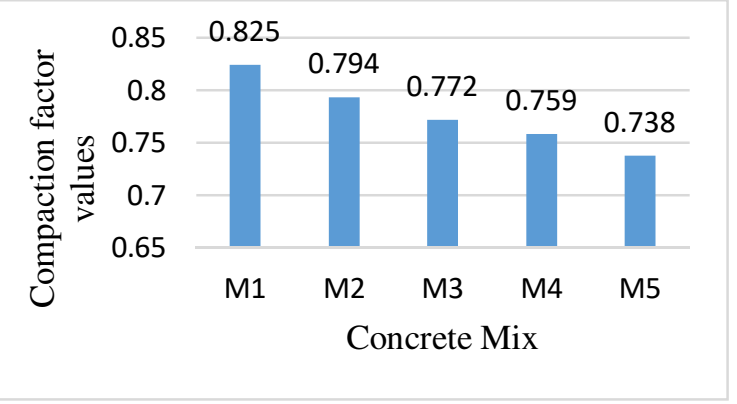

Fig. 3: Compaction aactor values for different concrete mix

mixes are prepared through the replacement of ordinary coarse aggregates with different percentages $0,25,50,75$ and $100 \%$ respectively of recycled aggregates. The casting of concrete cylinder is shown in Fig.4. Subsequently curing, clean and dry concrete cylinder is placed inside the compressive strength machine for testing using (ASTM C39) which is presented in Fig.5. The axial force is gradually applied on the sample until it breaks and extreme load is recorded. Further, the comparison is performed on compressive strength of ordinary concrete and the concrete produced with recycled coarse aggregates.

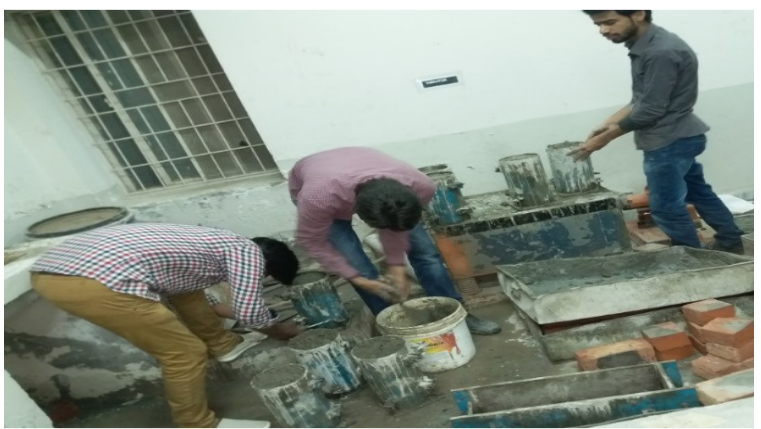

Fig.4: Casting of Cylinders 


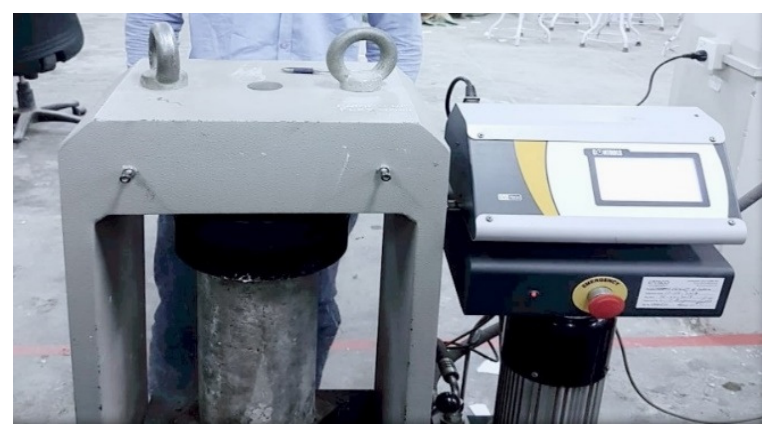

Fig. 5: Casting of Cylinders

The compressive strength variation is obviously perceived through the replacement of normal crush with different percentages of recycled aggregates which is revealed Fig.6.

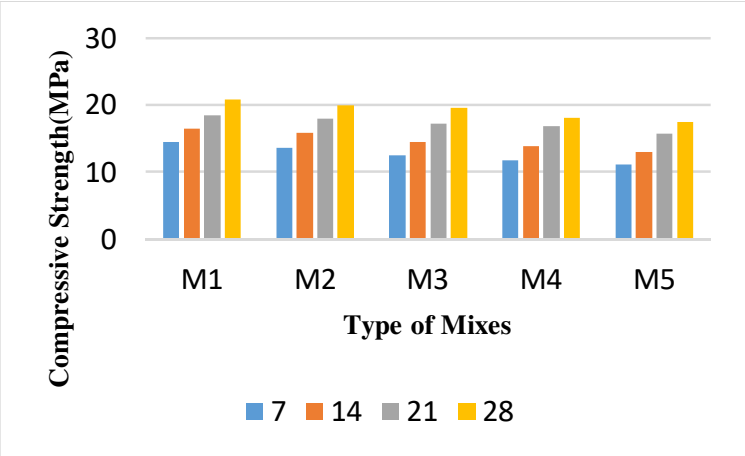

Fig. 6: Compressive Strength of Concrete by substituting the normal crush with various proportions of recycled aggregates

The compression test results show that there is a relationship between the reduction of compressive strength and proportion substitution of normal crush with recycled aggregates. The compressive strength is decreased as the percentage of recycled coarse aggregates is increased which is revealed in Fig.6. It is considerably observed that at 28 days of curing the compressive strength is reduced about $3.8 \%, 5.7 \%$, $12.9 \%$, and $15.8 \%$ for mix M2, M3, M4 and M5 respectively concrete manufactured by changing normal aggregates through $25 \%, 50 \%, 75 \%$ and $100 \%$ recycled aggregates shows a reduction of $3.8 \%, 5.7 \%$, $12.9 \%$ and $15.8 \%$ respectively in compressive strength than that of control mix ( $0 \%$ recycled aggregates) which is related to previous research [9].

The previous research shows that there are two different reasons of decrease in compressive strength of concrete such as additional water is required for mixing of concrete and quality of concrete is reduced when the quantity of recycled aggregates is increased than normal coarse aggregates. It should be necessary to soak the recycled coarse aggregates into water to improve the strength of concrete because of the more water absorbing capacity of recycled coarse aggregates [2].

\subsection{Splitting Tensile Strength}

Splitting tensile strength test is the indirect method of testing tensile strength of concrete because it is very difficult to determine the direct tensile strength. This experiment is performed to determine the splitting tensile strength (ASTM C496 and BS 1881 117-83) of five concrete mixes. The various values of splitting tensile strength are obtained for different mixes as shown in Fig. 7. To perform this test, a sample is positioned straight inside the plates and a uniform load is applied on the cylinder. Conferring to the concept of elasticity, this load produces constant tensile force until the concrete specimen will fail by splitting along a perpendicular face. The subsequent formula is used to calculate the splitting tensile strength.

$\mathrm{T}=\frac{2 \mathrm{P}}{\pi \mathrm{dl}}$

Here, $\quad T=$ Splitting tensile strength

$\mathrm{P}=$ Load

$\mathrm{d}=$ diameter of cylinder

$\mathrm{l}=$ length of cylinder

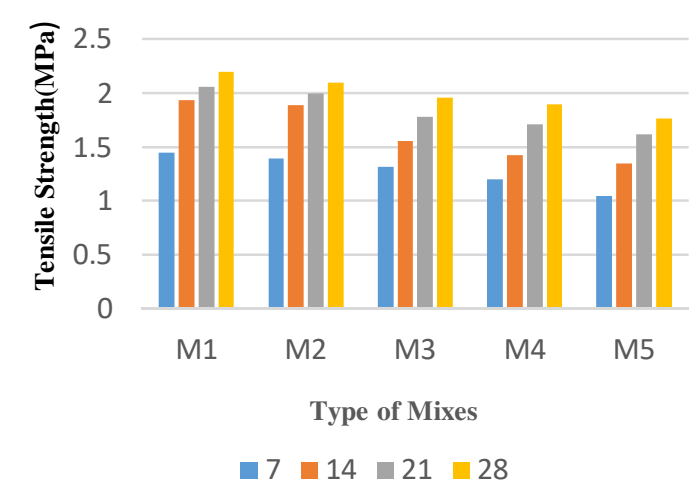

Fig. 7: Splitting tensile strength of concrete by substituting the normal crush with various proportions of recycled aggregates 
The test results show that splitting tensile strength is decreased by increasing the proportion of recycled aggregates. At 7 days, the concrete produced by replacing normal gravels with $25 \%, 50 \%, 75 \%$ and $100 \%$ recycled aggregates shows a reduction of $3.44 \%, 8.96 \%, 17.21 \%$, and $27.52 \%$ respectively in splitting tensile strength as compared to reference concrete mix M1 with 0\% replacement. Similarly, at 28 days the splitting tensile strength is reduced by $4.54 \%, 10.9 \%, 13.6 \%$, and $19.5 \%$ for different replacement ratios of recycled aggregate with normal aggregates.

\subsection{Comparison between Compressive and Splitting Tensile Strength}

Table 3 clearly shows that for each batch of concrete, the splitting tensile strength is almost $10 \%$ of the compressive strength. This argument is totally in line with the literature review of this study. Theoretically the splitting tensile strength of a concrete batch should vary between $9-11 \%$ of its respective compressive strength test results.

\begin{tabular}{|c|c|c|c|c|}
\hline \multicolumn{5}{|c|}{ Table 3: Comparison of Compressive and Splitting } \\
Tensile Strength Test Results \\
\hline $\begin{array}{c}\text { S. } \\
\text { No. }\end{array}$ & $\begin{array}{c}\text { Type } \\
\text { of } \\
\text { Mix }\end{array}$ & $\begin{array}{c}28 \text { days } \\
\text { Compressive } \\
\text { strength } \\
\text { (MPa) }\end{array}$ & $\begin{array}{c}28 \text { days } \\
\text { Split } \\
\text { Tensile } \\
\text { Strength } \\
\text { (MPa) }\end{array}$ & $\begin{array}{c}\% \text { age of } \\
\text { compressive } \\
\text { strength achieved } \\
\text { by splitting Tensile } \\
\text { strength }\end{array}$ \\
\hline 1 & M1 & 20.9 & 2.20 & $10.5 \%$ \\
\hline 2 & M2 & 20.1 & 2.10 & $10.4 \%$ \\
\hline 3 & M3 & 19.7 & 1.96 & $9.94 \%$ \\
\hline 4 & M4 & 18.2 & 1.90 & $10.4 \%$ \\
\hline 5 & M5 & 17.6 & 1.77 & $10.0 \%$ \\
\hline
\end{tabular}

\section{CONCLUSIONS}

In this research, the workability, compressive and splitting tensile strengths of concrete is determined by using different ratios of structure destroyed reinforced elements such as concrete slab, beam and piers etc. by means of a replacement of natural crush. The workability test results show the continuous reduction in slump and compaction factor values for all mixes as the quantity of recycled aggregate is increased in normal concrete as it requires extra water to make the concrete more workable. Further, it is also observed that at 28 days the concrete manufactured through substituting normal aggregates with 25, 50, 75 and
$100 \%$ recycled aggregates shows $3.8 \%, 5.7 \%, 12.9 \%$ and $15.8 \%$ respectively lessening of compressive strength as compared to control mix M1 ( $0 \%$ recycled aggregates). Similarly, at 28 days the splitting tensile strength is reduced by $4.54 \%, 10.9 \%, 13.6 \%$ and $19.5 \%$ for different replacement ratios of recycled aggregate with normal aggregates. Hence, it is concluded from the above results that the concrete strength decreases as the percentage replacement of normal aggregates with recycled aggregates is increased. Though, the strength is reduced by increasing the percentage of recycled aggregates but the results shows a minor reduction in strength (at 28 days the reduction is $3.8 \%$ as compared to control mix M1) from $0-25 \%$ replacement of recycled aggregates. The recycled aggregate concrete is usually preferable from $0-25 \%$ replacement of natural aggregates with recycled aggregates as it shows a slight decrease in strength as well as improve the environmental pollution issues and also reduce the cost of structure. Moreover, the splitting tensile strength of a concrete batch should vary between $9-11 \%$ of its respective compressive strength test results.

\section{ACKNOWLEDGMENT}

The Authors wish to thank all the kind people around who helped them making this research possible. Especially the Authors appreciatively acknowledge the help provided by the University of Lahore, Pakistan.

\section{REFERENCES}

1. Tarela E., Letelier V., Osses R., Cardenas J.P., Moriconi G., "Analysis of the variables that affect the strength of concrete with recycled aggregates from prefabricated pipes", Proceedings of the International Congress on Sustainable Construction and Eco-Efficient Solutions, Seville, 2015.

2. García-González J., Rodriguiz-Robles D., JuanValdes A., Moran-del Pozo J.M., Guerra-Romero M.I., "Pre-saturation technique of the recycled aggregates: Solution to the water absorption drawback in the recycled concrete manufacture", Materials, Vol. 7, No.9, pp. 62246236, 2014. 
3. Nakhi A.B., Alhumoud J.M., "Effectsof Recycled Aggregate on Concrete Mix and Exposure to Chloride", Advances in Materials Science and Engineering, 2019.

4. Jayakody S., Zimar A. M. Z., Ranaweera R. A. L. M., "Potential use of recycled construction and demolition waste aggregates for non-structural concrete applications", Journal of the National Science Foundation of Sri Lanka, Vol. 46, No.2, pp. 205-216, 2018.

5. Bahareh H, Imaninasab R., "Assessing the influence of construction and demolition waste materials on workability and mechanical properties of concrete using statistical analysis", Innovative Infrastructure Solutions, Vol 4, No.1, 2019

6. Khalid F.S., Azmi N.B., Sumandi K.A.S.M., Mazenan P.N., "Mechanical properties of concrete containing recycled concrete aggregate (RCA) and ceramic waste as coarse aggregate replacement", Proceedings of the $2^{\text {nd }}$ International Conference on Applied Science and Technology, Vol. 1891. No. 1, AIP Publishing, 2017.

7. Abdel-Hay A.S., "Properties of recycled concrete aggregate under different curing conditions", HBRC Journal, Vol.13, No.3, pp. 271-276, 2017.

8. Osei D.Y, "Compressive strength of concrete using recycled concrete aggregate as complete replacement of natural aggregate", Journal of Engineering, Computers and Applied Sciences, Vol. 2, No.10, pp. 26-30, 201.

9. Manjunath M., Prakash K. B., "Effect of replacement of natural aggregates by recycled aggregates derived from field demolished concrete on the workability and strength characteristics of concrete", International Journal of Civil and Structural Engineering, Vol. 6, No. 22015.

10. Naouaoui K., Azzeddine B., Toufik C., "Impact of Using Recycled Aggregates on Compressive Strength of Concrete", Proceedings of the 3rd International Conference on Smart City Applications, ACM, 2018.

11. Lamein F.R.S., Solikin M., Sunarjono I., "Effect of recycled coarse aggregate on concrete propertie", International Journal of Innovative Research in Science, Engineering and Technology, Vol. 4, No. 1, pp. 19060-19068, 2015.

12. Adnan S.A., Loon L.Y., Rahman I.A., Saman H.M., Soejoso M.V., "Compressive strength of recycled aggregate concrete with various percentage of recycled aggregate, 2007, Universiti Tun Hussein Onn Malaysia, Available online

at

http://eprints.uthm.edu.my/id/eprint/2029/1/CO MPRESSIVE_STRENGTH_OF_RECYCLED_

SURAYA_HANI_ADNAN.pdf. [Last accessed on 28th December 2019].

13. Khaoula N., Azzeddine B., Toufik C., "Impact of Using Recycled Aggregates on Compressive Strength of Concrete", Proceedings of the 3rd International Conference on Smart City Applications, pp. 1-5, ACM, October 2018.

14. Fawzy Y.A., "Impact of recycled gravel obtained from low or medium concrete grade on concrete properties", HBRC Journal, Vol. 14, No. 1, pp. 18, 2018.

15. Kanwal H., Arif S., Jawaid M. A., Farooq A., Khan M. A., "Effect on compressive strength of concrete using treated waste water for mixing and curing of concrete." Mehran University Research Journal of Engineering and Technology, Vol. 37, No. 2, pp. 445-452, 2018.

16. Akiyoshi Y., Sato T. Ueda O.K., Ito N., Okada H., "Study on compressive strength of concrete using low quality recycled coarse aggregates", Proceedings of 36th Conference on Our World in Concrete and Structures Singapore, 2011.

17. Koushkbaghi M., Jafarkazemi M., Mosavi H., Mohseni E., "Acid resistance and durability properties of steel fiber-reinforced concrete incorporating rice husk ash and recycled aggregate", Construction and Building Materials, Vol. 202, pp. 266-275, 2019. 